\title{
A inclusão escolar e as condições de acessibilidade: Um estudo preliminar na região sudoeste do Paraná
} Escolar inclusion and accessibility: preliminary study in southwest Paraná, Brozil

\author{
Andréia Paula Basei, ${ }^{1}$ Grezieli Fátima Cavasini. ${ }^{2}$ \\ 'Universidade Estadual de Maringá (UEM), Maringá, PR, Brasil. \\ ¿Universidade Paranaense, Unidade Universitária de Francisco Beltrão (Unipar), Francisco Beltrão, PR, Brasil.
}

Recebido em: fevereiro 2015 / Aceito em: março 2015

andreiabasei@yahoo.com.br

\section{RESUMO}

A acessibilidade na sua dimensão física-arquitetônica ganha destaque como uma das condições básicas para a inclusão educacional. Objetivo: analisar as condições de acessibilidade para pessoas com deficiência ou com mobilidade reduzida nas escolas públicas de municípios da região sudoeste do Paraná. Conhecer a legislação vigente sobre acessibilidade para traçar um paralelo com relação aos princípios e diretrizes assegurados em lei e as condições estruturais da realidade, bem como, analisar a percepção dos professores de Educação Física e direção das escolas sobre as condições de atendimento oferecidas aos alunos com deficiência. Método: A pesquisa é caracterizada como um estudo descritivo e de campo, centrada em fatos objetivamente observáveis, mapeando as condições de acessibilidade no ambiente escolar em vinte escolas públicas, escoIhidas aleatoriamente em treze municípios da região. Para a coleta das informações foram utilizados como instrumentos a observação sistemática e a entrevista semiestruturada. Resultados: observou-se que as escolas não atendem a todos os itens dispostos na legislação e que a maioria delas possui projetos para eliminação de barreiras físicas. Verificou-se que os docentes não se sentem preparados para trabalhar com alunos com deficiência e que não existe um projeto de capacitação por parte das escolas. Considerações finais: aponta-se a necessidade de que as condições de acessibilidade devem ser garantidas em todos os espaços escolares e que os docentes participem de programas de capacitação e formação continuada a fim de garantir a efetiva inclusão dos alunos com deficiência no ensino regular.

Palavras-chave: Ambiente escolar; Barreiras físicas/arquitetônicas; Legislação; Práticas pedagógicas; Educação Física.

\section{ABSTRACT}

Accessibility in your physical and architectural dimension is highlighted as one of the basic conditions for educational inclusion. Objective: analyze accessibility conditions of persons with disabilities or reduced mobility in public schools in counties southwest of Paraná. Meet current accessibility legislation to draw a parallel with respect to the principles and guidelines provided by law and the structural conditions of reality, and to evaluate the perception of physical education teachers and school management about the conditions of service offered to students with disabilities. Method: The research is characterized as a descriptive study and field, focused on objectively observable facts, mapping the accessibility conditions in the school environment in twenty public schools, randomly selected in thirteen municipalities. To collect the information were used as instruments for systematic observation and semistructured interview. Results: it was noted that schools do not meet all of the items laid out in the legislation and the majority have projects to eliminate physical barriers. It was found that teachers do not feel prepared to work with disabled students and that there is not a training project by schools. Final considerations: the accessibility conditions must be guaranteed in all school spaces and teachers must participate in training and continuing education programs to ensure the inclusion of students with disabilities in regular schools.

Keywords: School setting; Physical and architectural barriers; Legislation; Pedagogical practices; Physical Education. 


\section{INTRODUÇÃO}

Nos últimos anos, a atenção dispendida às pessoas com deficiência tem sido redobrada com relação ao fator inclusão social. As discussões se aprofundaram em termos de assegurar os seus direitos para o exercício da cidadania. Dessa forma, discutir a inclusão já é algo praticado constantemente na sociedade e, principalmente, no âmbito escolar. Debater o que, como e qual melhor forma, que a inclusão deve ser trabalhada se torna fundamental, considerando o papel da escola como agente modificador, que exerce influência direta no cotidiano de crianças e jovens, assim como em seu processo de desenvolvimento e aprendizagem.

O termo inclusão nos remete muitas vezes ao seu oposto, a exclusão. Mittler ${ }^{1}$, aborda esse aspecto considerando que, para algo ser incluído, primeiramente o mesmo deve estar excluído. E geralmente, o que faz a exclusão acontecer, poderia ser, em sua solução, o que resultaria em uma inclusão. Buscar formas de solucionar as barreiras que excluem indivíduos na sociedade é uma forma de se promover a inclusão, fator este de extrema importância e dificuldade.

Mittler ${ }^{1}$ destaca também que a inclusão escolar vai além da simples integração do indivíduo em um ambiente que deverá se adaptar às suas necessidades. Mas sim, compreende englobar todo o meio escolar, alterando principalmente o sistema de valores pessoais e profissionais de todos que atuam nesse âmbito.

Assim, promover a inclusão, dentre outros fatores, nos parece estar diretamente ligado a proporcionar condições de acessibilidade para todos aqueles que as necessitem. Sentir-se bem, em um ambiente escolar, é fundamental para qualquer indivíduo, para que desenvolva suas capacidades e habilidades e para que participe ativamente do processo de ensino e aprendizagem. Porém, quando a acessibilidade é uma questão de necessidade para um indivíduo, esse assunto deve ser tratado com mais atenção e, principalmente, com responsabilidade.

Nesse contexto, as condições de mobilidade e acessibilidade ganham importância, já que, tratam-se de condições essenciais para uma efetiva inclusão social. De acordo com a Lei $10.098 / 2000^{2}$, que estabelece normas gerais e critérios básicos de condições de acessibilidade, define esta como a "possibilidade e condição de alcance para utilização, com segurança e autonomia, dos espaços, mobiliários e equipamentos urbanos, das edificações, dos transportes e dos sistemas e meios de comunicação, por pessoa com deficiência ou com mobilidade reduzida". Sendo complementada por inúmeras leis e resoluções para atender as diversas particularidades destas pessoas, dentre as quais destacamos a lei $10.048 / 2000^{3}$, o decreto $5.296 / 2004^{4}$ e a NBR 9050/045.

Considerando especialmente o âmbito educacional, estas questões adquirem relevância no sentido de possibilitar o desenvolvimento cognitivo, motor, social e afetivo dos alunos com deficiência, já que, a acessibilidade pode ser considerada como um dos principais e primordiais fatores quando os objetivos estão voltados para a inclusão.

A inclusão é uma possibilidade que se abre para o aperfeiçoamento da Educação Escolar e para o benefício de todos os alunos, com e sem deficiência. Depende, contudo, de uma disponi- bilidade interna para se enfrentar as inovações e essa condição não é comum aos sistemas educacionais e aos professores em geral ${ }^{6}$.

Sendo assim, e conforme aponta Carvalho ${ }^{7}$ o que se pretende, na educação inclusiva, é remover barreiras, sejam elas extrínsecas ou intrínsecas aos alunos, buscando-se todas as formas de acessibilidade e de apoio de modo a assegurar (o que a lei faz) e, principalmente garantir (o que deve constar dos projetos políticos pedagógicos dos sistemas de ensino e das escolas e que deve ser executado), tomando-se as providências para efetivar ações para o acesso, ingresso e permanência bem sucedida na escola.

O objetivo desta pesquisa foi analisar as condições de acessibilidade para pessoas com deficiência ou com mobilidade reduzida nas escolas públicas de municípios da região sudoeste do Paraná, conhecer a legislação vigente sobre acessibilidade para traçar um paralelo com relação aos princípios e diretrizes assegurados em lei e as condições estruturais da realidade, bem como, analisar a percepção dos profissionais diretamente envolvidos no processo, isto é, direção e professores das escolas, enfatizando as práticas e professores da área da Educação Física.

Justifica-se a importância desta pesquisa, considerando o decreto-lei $n^{\circ} 5.296$ de 2004, que determina qu,e em cinco anos, todos os locais públicos estejam em condições acessíveis para todas as pessoas. Sendo a escola um local público dos mais frequentados atualmente, considera-se importante investigar como elas estão se adaptando ou já se adaptaram à legislação vigente. Por outro lado, ressaltamos a necessidade de conhecer a realidade educacional dessas escolas, para dar subsídios e facilitar o processo de conscientizar os profissionais envolvidos sobre a importância de promover a inclusão e a importância da acessibilidade para que ela efetivamente aconteça, assim como, incentivá-los a buscar recursos e formas para melhoria da estrutura da escola, formas de atendimento aos alunos com deficiência e do processo de ensino e aprendizagem como um todo.

\section{MÉTODO}

A presente pesquisa é caracterizada como um estudo descritivo, realizado por meio de pesquisa de campo, centrada em fatos objetivamente observáveis, mapeando as condições de acessibilidade no ambiente escolar em vinte escolas públicas, escolhidas aleatoriamente em treze munícipios da região sudoeste do Estado do Paraná, sendo eles: Ampére, Capanema, Chopinzinho, Enéas Marques, Flor da Serra do Sul, Francisco Beltrão, Manfrinópolis, Marmeleiro, Planalto, Realeza, Salgado Filho, Santo Antônio do Sudoeste e Verê. Após a escolha dos municípios, foram realizados contatos por telefone com os diretores ou responsáveis pelas escolas para o agendamento das visitas, para a realização das observações e das entrevistas, sendo que, para isto, solicitamos um documento da escola, autorizando a realização da pesquisa, bem como, o termo de consentimento livre e esclarecido dos entrevistados. Em ambos os documentos estava explícita a garantia de confidencialidade com relação à divulgação da identidade dos entrevistados e dos nomes das escolas.

Para a coleta das informações, foram utilizados 
como instrumentos a observação sistemática e a entrevista semiestruturada. As observações, realizadas pelas pesquisadoras, foram desenvolvidas com pautas voltadas para a acessibilidade na escola e a inclusão de alunos com deficiência, mobilidade reduzida ou necessidade especial. O instrumento de observação foi elaborado tendo como base: dados de identificação da escola, existência de alunos com deficiência ou com mobilidade reduzida, dados referentes às condições de acesso dos alunos com deficiência, nos quais se abordou o acesso ao prédio e seu interior, circulação interna; acesso por rampas e escadas; espaços das salas de aula, características dos mobiliários presentes, instalações sanitárias quanto à localização, lavatórios, tipo de piso e existência de barras de apoio, bem como suas características e a existência de bebedouros adaptados.

As pesquisadoras aplicaram também uma en trevista semiestruturada, realizada com a diretora ou responsável de cada escola e com um professor de Educação Física de cada escola selecionado de forma intencional, tendo como critério aquele que possuía mais tempo de serviço na escola. Esta entrevista teve como objetivo coletar dados sobre a existência, as condições de acesso e permanência dos alunos com deficiência nas dependências das escolas, assim como sobre o processo de ensino e aprendizagem com estes alunos.

Para a análise dos dados, foi utilizada a estatística descritiva por percentual, apresentação da frequência de ocorrências que facilitam a mobilidade do aluno com deficiência e análises qualitativas das condições encontradas na escola. A análise esteve pautada no que estabelece a Norma Brasileira (NBR) 9050 da Associação Brasileira de Normas Técnicas (ABNT), discriminando as condições ideais de acesso estabelecidas na lei, para permitir a mobilidade e permanência dos alunos com deficiência nas escolas.

\section{RESULTADOS E DISCUSSÃO}

Os resultados contemplam os dados das 20 escolas analisadas nos 13 municípios, em relação ao número de alunos com deficiência, acesso interno e externo e condições de acessibilidade. Importante destacar que destas, 15 escolas (75\%) possuem algum aluno com deficiência e 5 escolas (25\%) não possuem alunos com deficiência matriculados. No gráfico 1, é possível verificar o número de alunos de acordo com o tipo de deficiência que são atendidos no ensino regular nestas escolas. De acordo com os dados apresentados, a maioria dos alunos com deficiência que estão matriculados nestas escolas possui algum tipo de deficiência física: ou física, ou visual, ou intelectual ou auditivo.

\section{PERCEPC̣ÕES DA DIREC̣ÃO OU REPRESENTANTE DA ESCOLA E PROFESSORES SOBRE AS CONDIC̣ÕES DE ACESSIBILIDADE}

No primeiro contato com as escolas, consideramos relevante buscar informações com diretores ou representantes da escola, assim como professores de Educação Física sobre as condições de acessibilidade nas escolas, de acordo com o entendimento dos mesmos. Sobre estas entrevistas, de forma geral, pudemos perceber que a totalidade dos entrevistados possui a percepção de que a escola precisa de adaptações, precisa melhorar sua infraestrutura para melhor atender aos alunos com deficiências, uma vez que, algumas escolas inclusive não possuem sede própria, funcionando em espaços provisórios cedidos pelo município ou Estado o que dificulta ainda mais essa questão, pois são espaços que foram construídos com outras finalidades e sem condições nenhuma de acessibilidade para pessoas com necessidades especiais.

Por outro lado, tivemos também diretores de duas escolas que acreditam que as escolas possuem condições de atender a esses alunos, pois são escolas que foram construídas ou completamente reformadas com vistas a atender as condições especiais dos alunos.

Verificamos também que as limitações no atendimento aos alunos com deficiência vão além da falta de estrutura física ou material, mas também diz respeito à formação/qualificação dos profissionais, conforme apontam os entrevistados. Dentre estas dificuldades, é citada, principalmente, a necessidade de funcionários/ estagiários para auxiliar no atendimento aos alunos, visto que, na maioria das vezes estão incluídos em turmas grandes e o professor não consegue disponibilizar toda a atenção necessária para que esse aluno consiga acompanhar todo o processo de ensino e aprendizagem e desenvolver todas as atividades.

Sobre este aspecto também é mencionada a necessidade de qualificação profissional, pois grande parte dos professores não possui especialização para trabalhar com alunos com deficiência, alguns tampouco tiveram disciplinas na graduação voltadas para este aspecto. Por isso, conforme os entrevistados, existe a necessidade de investir na qualificação profissional dos professores. Estas constatações estão em consonância com a afirmação de Mantoan ${ }^{6}$ quando afirma que “os professores do ensino regular consideram-se incompetentes para lidar com as diferenças em sala de aula, es-

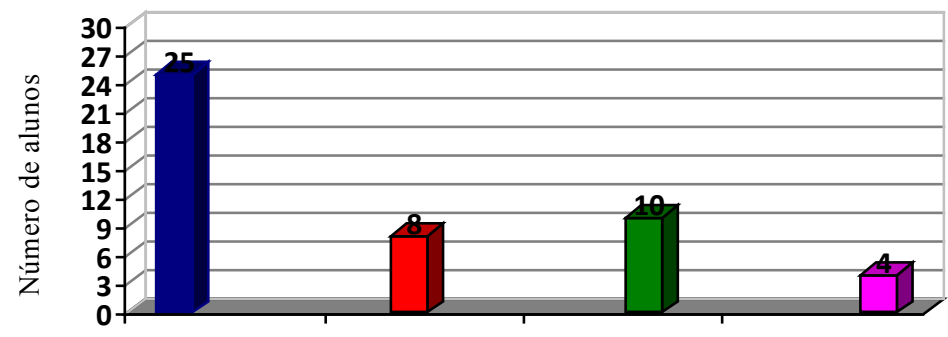

\begin{tabular}{|l|}
\hline Deficiência Física \\
$\square$ Deficiência Visual \\
$\square$ Deficiência Intelectual \\
$\square$ Deficiência Auditiva
\end{tabular}

Tipo de Deficiência

Gráfico 1 - Número de alunos com deficiência matriculados nas escolas segundo o tipo de deficiência. 
pecialmente para atender os alunos com deficiências".

Segundo Mittler", "a inclusão implica que todos os professores têm o direito de esperar e de receber preparação apropriada na formação inicial em educação e desenvolvimento profissional contínuo, durante sua vida profissional".

Para tanto, os sistemas de formação docente precisam ser repensados, com propostas de reconstrução para capacitar os professores através de um processo permanente de desenvolvimento profissional, envolvendo formação inicial e continuada, oportunizando assim a construção e ampliação de suas habilidades para trabaIhar o ensino inclusivo com o objetivo de alcançar todas as crianças e jovens nas suas diferentes necessidades de aprendizagens. Todavia, é importante também que o professor busque por esse desenvolvimento profissional, que tenha o entendimento de que a qualidade de suas práticas está diretamente relacionada no quanto investe em sua carreira profissional.

Com relação aos aspectos didáticos e pedagógicos as dificuldades estão relacionadas com a falta de material didático adequado, de recursos tecnológicos que poderiam facilitar a aprendizagem. De acordo com Zulian e Freitas ${ }^{8}$, os ambientes de aprendizagem, baseados nas tecnologias da informação e da comunicação, que compreendem o uso da informática, do computador, da internet, proporcionam atividades com propósitos educacionais, interessantes e desafiadoras, favorecendo a construção do conhecimento, no qual o aluno busca, explora, questiona, tem curiosidade, procura e propõe soluções. O computador é um meio de atrair o aluno com deficiência à escola, pois, à medida que ele tem contato com este equipamento, consegue abstrair e verificar a aplicabilidade do que está sendo estudado, sem medo de errar, construindo o conhecimento pela tentativa de ensaio e erro.

Sobre a questão ainda, Valente ${ }^{9,10}$, que pesquisa a validade do uso do computador pelos alunos com necessidades especiais, acredita que este recurso auxilia a qualquer que seja o grau de necessidade do aluno, até porque é composto de diversas ferramentas, e estas propiciam um trabalho lúdico-pedagógico, desde que mediado por profissionais qualificados.

Outros aspectos citados são as dificuldades para fazer o planejamento e adaptação das atividades e utilização de métodos de ensino adequados para atender às diferentes necessidades dos alunos com deficiência. Os professores relatam encontrar-se numa encruzilhada, ou seja, de planejar e selecionar os métodos de ensino com vistas ao aluno com deficiência ou visando atender à maioria dos alunos da classe.

E por fim, uma questão relatada, em um número reduzido das escolas pesquisadas, mas que merece ser mencionada, trata-se das formas de atendimento e atenção dados ao aluno pelo professor que acabam excluindo esses alunos das atividades, dificultando ainda mais a sua aprendizagem e desenvolvimento e também, questões de inclusão e aceitação pelo grupo.

\section{CONDIÇÕES DE ACESSIBILIDADE NA ESCOLA}

Um dos maiores problemas em relação à acessibilidade nas escolas é, sem dúvida, a existência de edificações e a utilização dos equipamentos escolares e mobiliário. Essa importância se dá devido ao entendimento de que,
[...] a estruturação do espaço físico, a forma como os materiais estão dispostos e organizados influenciam os processos de ensino e de aprendizagem e auxiliam a construção da autonomia, da estabilidade e da segurança emocional da criança. Para bem desenvolver sua identidade, é fundamental que ela sinta-se protegida e esteja inserida em um universo estável, conhecido e acolhedor. Os espaços são concebidos como componentes ativos do processo educacional e neles estão refletidas as concepções de educação assumidas pelo educador e pela escola ${ }^{11}$.

Considerando os alunos com deficiência, este aspecto merece atenção especial, já que, pode ser condição primordial, tanto para que o aluno frequente a escola, como também para que consiga acompanhar o processo de ensino e aprendizagem.

Todavia, percebe-se que essa questão não ganha total atenção por parte dos órgãos competentes, pois como pode ser constatado em nossas observações nas escolas visitadas, as escolas não possuem todas as adaptações necessárias, ou então são adaptações que não seguem ao estabelecido na legislação vigente, conforme pode ser observado nos seguintes pontos analisados:

* Rampas de acesso na entrada da escola e interiores: considerando o disposto na legislação, os desníveis de qualquer natureza devem ser evitados em rotas acessíveis, na impossibilidade de evitá-los, desníveis no piso de até $5 \mathrm{~mm}$ não demandam tratamento especial. Desníveis superiores a $5 \mathrm{~mm}$ até $15 \mathrm{~mm}$ devem ser tratados em forma de rampa (NBR 9050/04). Nesta pesquisa, verificou-se que $20 \%$ das escolas visitadas não possuem nenhum tipo de rampa de acesso. Considerando o percentual de escolas que possuem rampas (80\%), verificamos que estas não atendem completamente a legislação, já que, algumas possuem somente na parte interna da escola, para acesso a salas de aula, laboratórios, refeitório e ginásio e outras, somente na entrada da escola, tendo em seu interior várias escadas e degraus que dificultam a locomoção de alunos e funcionários com deficiência. É importante também considerar que, dentre as escolas que possuem rampas, em sua maioria são inadequadas por não apresentarem barras de apoio, por não possuírem largura adequada, por possuírem uma inclinação maior que o estabelecido nas normas, por não possuírem piso tátil ou qualquer outra forma de sinalização.

* Tipo de piso: verificou-se que $90 \%$ das escolas não possuem qualquer tipo de piso antiderrapante no seu interior, seja em escadas, rampas, corredores, salas ou outros espaços. Somente em duas escolas observamos a existência de piso antiderrapante em rampas e escadas. Estas características contradizem ao atendimento da legislação, a qual aponta que os pisos devem ter superfície regular, firme, estável e antiderrapante sob qualquer condição, que não provoque trepidação em dispositivos com rodas, além da necessidade de existir os pisos táteis de alerta e direcionais em ambientes internos e externos 5 .

* Barras de apoio: $10 \%$ das escolas não possuem qualquer tipo de barra de apoio, sendo que o restante das escolas possui, mas todas são parcialmente adequadas, 
isto é, existem barras em apenas alguns locais das escolas ou as barras estão em alturas e locais inadequados.

* Sinalização - 95\% das escolas não possuem qualquer tipo de sinalização para alunos ou funcionários com deficiência. Foram encontradas algumas formas de sinalização tátil, principalmente em pisos, e visual por meio de símbolos fixados nas paredes, ou pintados no chão e algumas setas direcionais em apenas uma escola. De acordo com a NBR 9050/045 , este é um aspecto relevante para promover a inclusão e deve abranger sinalização tátil - por meio de caracteres em relevo, braille e figura em relevo; visual - através de textos ou figuras; e sonoras - por meio de recursos auditivos nos diversos ambientes e espaços da escola.

* Mobiliário: somente duas das escolas visitadas possuem mobiliário adaptado ao tipo de deficiência dos alunos considerando especialmente suas necessidades no ambiente de sala de aula, laboratório de informática e refeitório. Sendo que, a grande maioria não possui qualquer mobiliário adaptado para atender os alunos, necessitando auxiliar esses alunos ou improvisar quando surge alguma necessidade especial.

* Sanitários: Somente uma escola possui sanitários adequados para alunos com deficiência, quatro escolas não possuem sanitários adaptados e todas as demais atendem parcialmente essa necessidade, uma vez que, os sanitários existem, mas não atendem a todos os requisitos das normas.

* Bebedouros: Somente três escolas possuem bebedouros adaptados; nas demais escolas os bebedouros não são adequados para alunos com deficiência, por serem altos ou estarem em locais inapropriados de difícil acesso.

Conforme podemos observar,

As barreiras arquitetônicas são os maiores empecilhos para as pessoas com necessidades educacionais especiais - deficiência, que fazem uso de cadeiras de rodas, bengalas ou muletas para se locomoverem. Não apenas dificultam, mas, muitas vezes, impedem completamente sua inserção na sociedade. Tais barreiras nem sempre são voluntárias, mas sem dúvida, são fruto de imenso descaso e da não obediência às leis vigentes ${ }^{12}$.

Por outro lado, a partir das informações coletadas é possível notar que, na maioria das vezes, só se pensa na solução de algum problema, quando se depara com ele. Algumas escolas somente se preparam ou pensam em construir uma rampa, quando aparece um aluno com cadeira de rodas. Só pensam em utilizar os recursos tecnológicos, quando recebem algum aluno que precisa de programas auxiliares para facilitar a sua aprendizagem; em adequar sanitários e mobiliários, quando os alunos com deficiência são matriculados na escola. Isso acaba gerando inúmeras dificuldades, pois estamos falando de escolas públicas, que dependem da liberação de recursos financeiros para realizar as reformas necessárias e que para isso, é inevitável todo um processo burocrático por meio dos órgãos governamentais, o que acaba levando algum tempo, até que isso seja possível.

\section{CONDIÇÕES DE ACESSIBILIDADE PARA AS AULAS DE EDUCAÇÃO FÍSICA}

A prática de atividades físicas é de extrema importância para os alunos com deficiência, seja por questões de melhorias no seu desenvolvimento motor, ou pelos possíveis benefícios nos aspectos cognitivo, social e afetivo. Contudo, o que se pode observar com relação a este aspecto é que existe, por parte dos professores, um déficit na formação profissional para trabalhar com esses alunos, uma vez que, $90 \%$ dos entrevistados mencionaram esta questão ao serem indagados sobre as principais dificuldades de se trabalhar.

A falta de capacitação específica dos professores de Educação Física para trabalhar com estes alunos é destacada pelo fato de que muitos deles não tiveram nenhuma disciplina na graduação que tratasse dos alunos com deficiência e também não participaram de outros cursos sobre a temática. Ao verificar esta situação, percebe-se claramente, a necessidade de cursos para capacitação para estes professores nesta área.

Os cursos de formação são definidos por Wood, citado por Marcelo García ${ }^{13}$, como “um grupo de pessoas que participam, durante um certo período de tempo, em atividades estruturadas para alcançar determinados objetivos e realizar tarefas estabelecidas de antemão, as quais levam a uma nova compreensão e conduta profissional". Estes cursos poderiam contribuir então, como a melhoria das ações dos professores direcionadas aos alunos com deficiência, já que, de acordo com Bell, citado por Marcelo Garcia ${ }^{13}$, as vantagens vão no sentido de aumentar os conhecimentos, melhorar as competências, proporcionar um espaço de reflexão sobre a prática profissional e oportunizar que os professores escolham as temáticas que acharem mais interessantes.

No entanto, há que se considerar que os cursos de capacitação por si só, não irão garantir a melhoria no atendimento aos alunos, já que,

a formação de educadores para uma escola inclusiva não se restringe a cursos de capacitação, reciclagem, aperfeiçoamento e outros que são oferecidos em diferentes instâncias educacionais. A reflexão individual sobre a prática em sala de aula deve se somar ao conhecimento científico já existente, sobre estratégias de ensino mais dinâmicas e inovadoras ${ }^{14}$.

Por outro lado, foi possível perceber que as condições físicas e materiais disponibilizadas pelas escolas também são fatores que limitam o processo de ensino e aprendizagem na Educação Física.

Com relação a isto, verificamos que a acessibilidade para os locais de prática das atividades são inadequadas em todas as escolas observadas. Foram observados aspectos básicos como: rampas de acesso, barras de apoio, tipo de piso e sinalização. Verificamos que apenas seis das escolas observadas possuem rampas de acesso ao ginásio de esportes, contudo, estas não estão adequadas com relação ao grau de inclinação, ao tipo de piso e a falta de barras de apoio laterais. Os demais itens observados, como piso antiderrapante e sinalização também estão ausentes nos locais das aulas de Educação Física.

Foi observado ainda que algumas escolas não possuem um local próprio para a realização dessas aulas, utilizando-se de estruturas pertencentes à comunidade local para isso. $\mathrm{O}$ acesso para estes locais aparece ainda mais dificultado, pois geralmente ficam a alguns metros da escola, necessitando que os alunos saiam da escola, 
atravessem ruas e utilizem calçadas para chegar ao local. Com relação aos materiais, a maioria dos professores menciona que as escolas não possuem materiais específicos para atender a estes alunos como bolas com guizo, cadeiras específicas, jogos pedagógicos, entre outros.

\section{CONSIDERACִÕES FINAIS}

Ao final desta pesquisa, observou-se que as escolas ainda não estão preparadas adequadamente para atender à Lei 5296/04, a qual previa que até o ano de 2009 os governos municipais, estaduais e federal tinham o compromisso de finalizar os projetos de adaptação dos espaços para atender as pessoa com deficiência.

Da mesma forma, verificou-se que as escolas não estão obedecendo a NBR 9050/04, já que, nenhuma das escolas estava adaptada em todos os itens avaliados. No entanto, a maioria possui um ou mais itens adaptados pensando nas necessidades dos alunos com deficiência física. Para os demais tipos de deficiência, as condições de acessibilidade se tornam ainda mais precárias. Apesar disso, é importante ressaltar que um grande número de escolas apresentam projetos para eliminação das barreiras arquitetônicas e ambientais, o que, provavelmente, ocorrerá nos próximos anos caso exista a liberação de verbas por parte dos governos estaduais e federal para a execução das obras.

Algumas dificuldades encontradas foram quanto à falta de preparo do corpo docente para trabalhar e orientar os alunos com deficiência, tanto nas atividades físicas ou de recreação, como nas atividades em sala de aula. Com relação à postura não existe nenhum treinamento que os habilite para desempenhar estas funções.

De acordo com a NBR 9050/04, a acessibilidade deve ser garantida a todos os ambientes da escola, salas de aulas, laboratórios de informática, salas de aulas práticas, bibliotecas, sala dos professores, secretarias, coordenação, as áreas esportivas, refeitório, sanitários, o pátio, enfim todo o ambiente escolar. $O$ que não está efetivamente acontecendo, como pode-se verificar neste estudo, pois se considerados todos os aspectos estabelecidos na norma, a totalidade das escolas pesquisadas não está em conformidade com as exigências propostas pela legislação.

Neste contexto, surgem inúmeros questionamentos com relação aos direitos das pessoas com deficiência e as possibilidades que efetivamente existem de promover a inclusão social e educacional, já que, o que vem ocorrendo até então não passa de uma integração das pessoas com deficiência, nos diferentes âmbitos sociais. Fato este que deveria estar acontecendo há muitos anos pois é previsto desde a Constituição Federal de $1988^{15}$ que em seu artigo 208 que estabelece como dever do Estado "o atendimento educacional especializado aos portadores de deficiência, preferencialmente na rede regular de ensino". Da mesma forma, a Lei de Diretrizes e Bases da Educação 9.394/9616, também prevê o atendimento à educação especial, oferecida preferencialmente na rede regular de ensino, para crianças com deficiência. Como garantir que estes direitos sejam atendidos se a precarização dos espaços de atendimento é evidente, assim como o despreparo de muitos profissionais para trabalhar com estes alunos?

Para finalizar, reconhecemos que os debates e reflexões devem ser constantes no intuito de buscar algumas soluções para os problemas vividos, atualmente. Ressaltamos também a necessidade de outros estudos mais detalhados sobre cada contexto escolar, especialmente envolvendo gestores educacionais e professores por meio de um espaço de reflexão sobre as condições para atendimento de alunos com deficiências na escola e construção de projetos e definição de prioridades para buscar efetivamente promover a inclusão escolar.

\section{REFERÊNCIAS}

1. Mittler P. Educação Inclusiva: Contextos Sociais. São Paulo: Artmed, 2003.

2. BRASIL. Lei $n^{\circ} 10.098$, de 19 de dezembro de 2000. Estabelece normas gerais e critérios básicos para a promoção da acessibilidade das pessoas portadoras de deficiência ou com mobilidade reduzida, e dá outras providências. Disponível em: <http:// www.mec.gov.br. Acesso em: 10 ago. 2013.

3. BRASIL. Lei 10.048 de 8 de novembro de 2000. Dá prioridade à pessoas que especifica e dá outras providências. Disponível em: <http:// www.mec.gov.br. Acesso em: 10 ago. 2013.

4. BRASIL. Decreto $n^{\circ}$ 5.296, de 2 de dezembro de 2004. Estabelece normas gerais e critérios básicos para a promoção da acessibilidade das pessoas portadoras de deficiência ou com mobilidade reduzida, e dá outras providências. Disponível em: <http:// www.planalto. gov.br/CCIVILato2004>. Acesso em: 5 ago. 2014.

5. ASSOCIAC̣ÃO BRASILEIRA DE NORMAS TÉCNICAS. NBR 9050: Acessibilidade a edificações, mobiliário, espaços e equipamentos urbanos. Rio de Janeiro, 2004.

6. Mantoan MTE. Inclusão Escolar: o que é? Por quê? Como fazer? 2. ed. São Paulo: Moderna, 2006.

7. Carvalho RE. Educação Inclusiva: com os pingos nos "is". Porto Alegre: Mediação, 2004.

8. Zulian MS, Freitas SN. Formação de professores na educação inclusiva: aprendendo a viver, criar, pensar e ensinar de outro modo. In: Revista Educação Especial, Universidade Federal de Santa Maria, n. 18, 2001.

9. Valente JA (org.). Liberando a mente: computadores na educação especial. Campinas: UNICAMP, 1991.

10. Valente JA. O uso do computador na inclusão da criança deficiente. In: MANTOAN, MTE. A integração de pessoas com deficiência. São Paulo: Memnon, 1997.

11. Frison LMB. O espaço e o tempo na Educação Infantil. In: Revista Ciênc. let., Porto Alegre, n. 43, p. 169-180, jan./ jun. 2008. Disponível em: <http://www.fapa.com.br/ cienciaseletras $>$. Acesso em: 02 maio. 2014.

12. BRASIL. A inclusão de alunos com necessidades educacionais especiais - deficiência física. Elaboração: SILVA, AF; CASTRO, ALB; BRANCO, MCMC. Brasília: Ministério da Educação, Secretaria de Educação Especial, 2006.

13. Marcelo García C. Formação de professores: para uma mudança educativa. Porto: Porto Ed, 1999.

14. Ferreira WB. Educação inclusiva: Será que sou a favor ou contra uma escola de qualidade para todos? Inclusão Revista de Educação Especial. Ano I, nº 1, out. 2005.

15. BRASIL. Constituição Federal. Brasília: Senado Federal, 1988.

16. BRASIL. Ministério da Educação. Lei 9.394/96. Estabelece as Diretrizes e Bases da Educação Nacional. Brasília, 1996. 